\title{
A ADESÃO AO PROGRAMA NACIONAL DE APOIO À GESTÃo ADMINISTRATIVA E FISCAL NOS MUNICÍPIOS BRASILEIROS: O CASO DOS MUNICÍPIOS DO ESTADO DO RIO GRANDE DO SUL
}

\author{
A SUBSCRIPTION TO NATIONAL PROGRAM TO SUPPORT THE ADMINISTRATIVE \\ AND FISCAL MANAGEMENT IN BRAZILIAN MUNICIPALITIES: THE CASE OF THE \\ MUNICIPALITIES OF THE STATE OF RIO GRANDE DO SUL
}

\author{
Sandra Regina Toledo Santos \\ sandratche@yahoo.com.br \\ Universidade de Passo Fundo
}

\author{
Caroline Pimentel \\ tchecarol@yahoo.com.br \\ Universidade de Passo Fundo
}

\begin{abstract}
RESUMO
Os municípios têm buscado o incremento na arrecadação tributária como suporte para atender às demandas da população. Para tanto, programas de apoio financeiro têm sido lançados para modernizá-los e incrementar essa fonte de receita, como é o caso do Programa Nacional de Apoio à Gestão Administrativa e Fiscal nos Municípios Brasileiros. Este artigo aborda a percepção dos gestores das Unidades de Execução Municipal (UEM) sobre o PNAFM quanto à modernização dos Municípios gaúchos integrantes do programa e o objetivo principal consiste em identificar a percepção desses gestores quanto aos resultados gerados, especificamente até o final ano de 2009. A metodologia utilizada foi descritiva, com enfoque qualitativo, delineada por levantamento, com uma pesquisa junto ao site do Ministério da Fazenda para a obtenção dos dados gerais do programa e de um questionário enviado aos responsáveis pela execução do PNAFM nos oito municípios que apresentavam ações em andamento no período de 2007 a 2009. Os resultados encontrados indicaram quesitos com baixo índice de implantação do projeto conforme previsto inicialmente quanto a processos mais otimizados, mas observou-se que a ampliação sistemática de novas linhas de crédito aos Municípios gera melhores resultados à gestão municipal no que se refere a reformulação de processos internos, de reorganização funcional, na estrutura administrativa e nas condições de modernização físicas com a utilização de recursos tecnológicos, formando o ambiente mais organizado e voltado aos resultados mais efetivos na administração municipal.
\end{abstract}

Palavras-chave: Programa. Gerenciamento. Municípios. Arrecadação Tributária.

\begin{abstract}
The municipalities have sought an increase in tax revenues as a support to meet the demands of the population. For this purpose, financial aid programs have been launched to modernize them and increase this source of revenue, such as the National Program Support Administrative and Fiscal Management in Brazilian Municipalities. This article discusses the perception of managers of Municipal Implementation Units ( EMU ) on the PNAFM as the modernization of the gauchos Municipalities members of the program and the main objective is to identify the perceptions of these managers as to the results generated specifically by the end of 2009. The methodology used was descriptive and qualitative approach, outlined by lifting to a survey by the Ministry of Finance website to obtain general information on the program and a questionnaire sent to those responsible for implementing the PNAFM the eight municipalities with shares progress in the period 2007-2009. Questions the results indicated a low rate of implementation of the project as originally planned as the most optimized processes, but it was
\end{abstract}


observed that the systematic extension of new credit lines to municipalities generates better results for municipal management regarding the redesign of internal processes of functional reorganization in the administrative structure and the physical conditions of modernization with the use of technological resources, forming more organized and more effective results returned to the municipal administration environment.

Key words: Program. Management. Municipalities. Tax revenues.

Artigo recebido em: 04/10/2012; Aceito em: 19/04/2014

\section{INTRODUÇÃO}

No atual cenário global com a inserção de inovações tecnológicas, torna-se imprescindível a adoção de constantes mudanças, como a modernização da estrutura organizacional e práticas gerenciais, tanto no setor privado quanto na esfera pública, que, por sua vez, administra os recursos disponíveis para a manutenção governamental, realizando investimentos para a melhoria da qualidade de vida da população.

Dentre as atribuições dos administradores do patrimônio público destaca-se o zelo pelo bemestar coletivo da população por meio do desenvolvimento local, buscando exercer da melhor forma possível a prestação dos serviços à população.

Nessa perspectiva, Guimarães, Cavalcanti e Affonseca (2004) destacam que na década de 1990, a partir do processo do neoliberalismo e da reforma administrativa, as organizações públicas passaram a entender a extrema necessidade da substituição de um modelo de gestão burocrático ultrapassado, o qual já não atendia às expectativas das atuais demandas oriundas dos cidadãos em geral, por um modelo de gestão baseado na racionalização, flexibilidade e autonomia, buscando atender de maneira ágil e eficiente às demandas sociais por serviços públicos de qualidade.

Tais inovações gerenciais no setor público refletiriam em mudanças na qualidade dos serviços prestados, advindas basicamente das reformulações estratégicas, políticas públicas, controle de processos e acompanhamento de resultados.

O enfoque de Bresser Pereira (1996) é de que na busca por uma administração pública gerencial devem ser considerados os "problemas não só de crescimento, da decorrente diferenciação de estruturas e complexidade crescente da pauta de problemas a serem enfrentados, mas também de legitimação da burocracia perante as demandas da cidadania."

Logo, ao modificar a sua maneira de governar, pela adoção de uma gestão pró-ativa e de inovações tecnológicas, o gestor deve priorizar a busca pela excelência organizacional visando ao alcance da eficiência na gestão e, consequentemente, a uma utilização racional dos recursos para a promoção dos serviços sociais, de modo a proporcionar benefícios para a sociedade. A partir do novo formato delineado para esse gerenciamento, passaram a surgir alternativas de financiamento a fim de dotarem as instituições de condições financeiras para adequarem suas estruturas ao novo modelo.

Dentre as linhas de financiamento ofertadas por meio do governo federal aos Municípios brasileiros, para de modernizar suas estruturas administrativas, destacam-se o Programa de Modernização da Administração Tributária e da Gestão dos Setores Sociais Básicos (PMAT), criado em 1997 para dotar os Municípios de recursos que proporcionem maior eficiência e controle sobre a arrecadação dos tributos locais e, como objeto desse estudo, o Programa Nacional de Apoio à Gestão Administrativa e Fiscal dos Municípios Brasileiros (PNAFM),

R. Cont. Ufba, Salvador-Ba, v. 8, n. 3, p. 05 - 20, set-dez 2014 
criado em 2001 para modernizar a gestão administrativa e fiscal, contribuindo para o processo de incremento da arrecadação (BRASIL, 2009).

Desde então, os municípios que enfrentavam dificuldades em âmbito administrativo e do processo de gestão, passaram a buscar alternativas que minimizassem os efeitos negativos decorrentes desse cenário. Com isso, o PNAFM veio para contribuir à melhoria da eficácia administrativa e da gestão racional dos recursos dos orçamentos públicos, por meio da modernização e fortalecimento das administrações municipais, proporcionando assim um equilíbrio fiscal auto-sustentável dos municípios.

Nesse contexto, este trabalho tem a seguinte questão de pesquisa: Qual a percepção dos gestores das Unidades de Execução Municipal (UEM) sobre o PNAFM nos Municípios gaúchos que aderiram ao programa? O objetivo principal consiste em identificar a percepção dos gestores das UEM sobre a adesão ao PNAFM nos municípios do Estado do Rio Grande do Sul até o final ano de 2009.

Os resultados obtidos permitirão o melhor acompanhamento e prestação de contas da gestão dos agentes públicos a partir da transparência das informações relacionadas à adesão ao programa, bem como dotar os gestores de informações relevantes que estimulem a busca por recursos dessa natureza para melhor gerenciar os governos locais. Ressalta-se a escolha do tema em virtude do PNAFM não buscar somente melhorias no processo de arrecadação, mas sim, em conduzir novas metodologias de gestão no serviço público daqueles que integram o programa, sem desprezar as possíveis dificuldades encontradas para a aderência às regras vinculadas a execução do programa, como, por exemplo, a necessidade de cumprimento das obrigações orçamentárias e financeiras do contrato.

Este trabalho está estruturado em cinco seções: a primeira inicia por esta introdução; a segunda apresenta o referencial teórico, a terceira apresenta os procedimentos metodológicos, já na quarta apresentam-se os resultados da pesquisa; e, por fim, na quinta seção constam as conclusões, seguida das referências bibliográficas.

\section{REFERENCIAL TEÓRICO}

Nesta seção são abordados temas como a transposição da administração burocrática à gerencial no setor público, a gestão da qualidade no serviço público, instrumentos gerenciais de controle na esfera pública e a busca pela eficiência e, por fim, o PNAFM como programa modernizador dos Municípios brasileiros.

\subsection{A transposição da administração burocrática à gerencial no setor público}

As primeiras manifestações sobre o gerenciamento público aconteceram em 1979, na GrãBretanha, no governo da primeira-ministra Margaret Thatcher e em 1980, nos Estados Unidos, no mandato de Ronald Reagan. A necessidade por mudanças estruturais foi impulsionada pela busca por soluções nas crises fiscais dos Estados e tinha como objetivo tornar a administração pública mais eficiente, priorizando a otimização de resultados pela redução de gastos e, consequentemente, protegendo o patrimônio público (BRESSER PEREIRA, 1996; SANTOS, 2003).

Bresser Pereira (1996) escreve que no Brasil a primeira reforma da administração pública foi a burocrática de 1936. Já no governo de Castelo Branco, aconteceu outra tentativa de promoção da descentralização por meio do Decreto-Lei $n^{\circ}$ 200/1967, que visava transferir a

R. Cont. Ufba, Salvador-Ba, v. 8, n. 3, p. 05 - 20, set-dez 2014 
responsabilidade pelas atividades de produção de bens e serviços para autarquias, fundações, empresas públicas e sociedades de economia mista.

Para o autor, almejava-se com isso a obtenção da racionalidade administrativa, planejamento, orçamento, bem como a descentralização e controle de resultado. Todavia, somente em meados da década de 1990 efetivamente começou a ser amadurecida a proposta de implantação de técnicas gerenciais a fim de superar a crise do Estado na década de 1980 e enfrentar a economia globalizada.

A partir da formulação da Constituição de 1988, emergiu fortemente a crise da administração pública burocrática, mas o seu real início deu-se ainda durante o regime militar, através dos procedimentos facilitados para o recrutamento de administradores de alto escalão nas empresas estatais, o que inviabilizou a consolidação de uma burocracia profissional no país, pelo desenvolvimento de um sistema de concursos e redefinição de carreiras (BRESSER PEREIRA, 1996).

Assim, as mudanças nos procedimentos do governo tornaram-se indispensáveis à modernização administrativa, culminando numa reforma que restringiu a administração burocrática e ampliou o enfoque gerencial para combater as crises que impediam a obtenção de resultados positivos, a credibilidade e o crescimento da economia brasileira.

Santos (2003) relata que o governo de Fernando Henrique Cardoso foi o maior precursor desta reforma, transformando a antiga Secretaria da Presidência no Ministério da Administração Federal e Reforma do Estado (MARE), encarregada da reconstrução do Estado brasileiro, especialmente com as reformas fiscal e previdenciária.

Assim, o Estado, que inicialmente tinha como principal objetivo proteger as respectivas economias da competitividade internacional passa a ter um novo papel, o de facilitador da economia nacional, proporcionando avanços no cenário internacional ao delinear os processos de gestão nos moldes da nova administração pública, dotando de mudanças significativas como, por exemplo, a reestruturação administrativa e a redução dos procedimentos burocráticos de modo interno.

\subsection{A gestão da qualidade no serviço público}

A partir da transição ocorrida nas últimas décadas, conforme descrito anteriormente, o setor governamental passou a preconizar, embora que gradativamente, a busca por melhor qualidade dos serviços no atendimento à população. Entretanto, o resultado disso, dependia também de mudanças na consciência cultural dos dirigentes.

Guimarães, Cavalcanti e Affonseca (2004) apontam que a colaboração e o comprometimento dos envolvidos nos processos são fundamentais para o alcance de sucesso em qualquer inovação.

Bresser Pereira (1996) destaca que ao ser deflagrado esse processo de reforma na década de 1990, inicialmente foi desencadeada desconfiança nos diversos níveis hierárquicos do funcionalismo público. Contudo, após serem apresentadas as propostas de reforma que contemplavam questões como estabilidade dos servidores, regime de trabalho, sistema previdenciário e os tetos de remuneração, começaram as manifestações de apoio dos escalões mais altos do governo e da opinião pública.

Para o mesmo autor, mais tarde tornou-se generalizada a convicção de que a transição da estrutura burocrática para a gerencial era necessária, a fim de ajustar fiscalmente os Estados e Municípios, proporcionando agilidade e qualificação para o setor público no atendimento aos anseios dos cidadãos.

O processo evolutivo pode ser considerado como um "elemento primordial dentro da renovação inspirada por um paradigma de uma administração gerencial, orientada para atender um

R. Cont. Ufba, Salvador-Ba, v. 8, n. 3, p. 05 - 20, set-dez 2014 
cidadão-cliente e mobilizar seus recursos humanos em função das exigências de qualidade, flexibilidade e criatividade" (INAP, 1997, p. 2).

Para tanto, Osborne e Gaeble (1997, p. 371) descreviam que "os governos empreendedores podem escolher não só a melhor alternativa para a prestação dos serviços, como também entre inumeráveis variações e combinações". Sob esse vértice, ficava descrito que a busca por melhores alternativas e necessárias ao bom andamento das atividades internas do setor público, deveria estar alinhada a nova forma de atuação governamental.

Para a obtenção de resultados satisfatórios deveria ser instituída uma sistemática de alternativas viáveis e que viesse ao encontro do proposto pelo governo. Na ótica de Cavalheiro e Flores (2001, p.12), isso se relaciona ao planejamento e as diretrizes estratégicas que requerem profissionalismo, visto que deve ser contemplada "a situação atual, a necessidade de serviços e obras à população, o que e quanto se poderá atender, e, como se fará para chegar ao planejado". O planejamento ao contemplar a missão da organização e sua visão de futuro, poderá se tornar um instrumento que possibilite a otimização dos resultados e, com isso, gerar benefícios aos usuários do sistema onde este estiver implantado.

Com essas perspectivas, Guimarães, Cavalcanti e Affonseca (2004, p. 6) argumentam que "as inovações gerenciais equivalem-se às mudanças organizacionais de natureza estrutural, estratégica, cultural, tecnológica, humana ou de qualquer outro componente, capaz de gerar impacto em partes ou no conjunto da organização". Os autores enfatizam a importância de uma liderança forte e imperativa na gerência, bem como a função da comunicação, reduzindo resistências e aumentando o grau de comprometimento dos envolvidos na organização.

O enquadramento apontado pelos mesmos autores é de que há dois motivos que levam as organizações a adotarem novos métodos de gestão: a influência externa, derivada de organizações de fora do grupo pelas escolhas da organização dentro do grupo e a incerteza causada pela pouca clareza dos seus objetivos. Com isso, os autores pesquisaram cinco organizações públicas para levantar as principais razões para essa implementação, destacandose os estímulos gerados pelo Plano Plurianual quanto à definição de programas públicos, ao Programa de Qualidade no Serviço Público (PQSP) e, ainda, devido à escassez de recursos financeiros.

Sob esse vértice, Bezerra Filho (2002) já destacava que o PQSP tinha como pressuposto um modelo de gestão composto por fatores determinados para o alcance de níveis de excelência, como a liderança, estratégia e planos, o cidadão como cliente, informações mais precisas para a tomada de decisão, a gestão de pessoas no setor público, redefinição de processos e a busca por resultados.

As técnicas mais empreendidas relacionavam-se aos programas baseados nas técnicas de qualidade, incluindo mecanismos de planejamento e avaliação do trabalho (CAVALHEIRO; FLORES, 2001).

Percebe-se que para o êxito na implantação dos novos processos gerenciais a realização de avaliações constitui-se num ponto essencial, pois compara o modelo de gestão ideal em contrapartida às atividades que foram ou estão sendo desenvolvidas. Desse modo, podem-se ajustar os programas que se encontram em fase de implantação, qualificando-os e formulando novas ações que viabilizem os resultados pretendidos pelo gestor.

A evidenciação de resultados práticos pode ser refletida pelo acompanhamento por meio de indicadores de desempenho e dos custos dos programas de governos. Torna-se então, quesito fundamental, gerir com qualidade (eficiência) e fazer mais com menos (CAVALHEIRO; FLORES, 2001).

Outro parâmetro qualitativo utilizado na administração pública gerencial consiste na participação de grupos externos de consultorias técnicas na implantação de instrumentos modernos de gestão. Esse mecanismo transmite mais confiabilidade, transparência,

R. Cont. Ufba, Salvador-Ba, v. 8, n. 3, p. 05 - 20, set-dez 2014 
profissionalismo e credibilidade ao órgão público (GUIMARÃES; CAVALCANTI; AFFONSECA, 2004).

Com a Lei de Responsabilidade Fiscal (LRF/2000), outros indicativos de qualidade nos processos públicos foram reforçados, como os controles internos, a ampla e objetiva divulgação dos atos administrativos como forma de transparência, as prestações de contas à sociedade de modo efetivo e contínuo, a implantação de custos nos setores governamentais e a divulgação de resultados.

\subsection{Instrumentos gerenciais de controle e a busca pela eficiência pública}

O uso de métodos administrativos que proporcionam maior controle e que promovam um gerenciamento otimizado, devem ser inseridos a fim de que Contabilidade auxilie o gestor de modo mais eficiente e possibilite informações mais precisas. Aliado a isso, são diretrizes importantes nesse contexto, os controles internos mais profícuos para gerar maior economia de recursos e eficácia nos processos da gestão, bem como facilitar o controle externo realizado pelos Tribunais de Contas.

Reis et al (2007) descreve que a partir da edição da Lei 4320/1964, deu-se ênfase à Contabilidade do setor público, pela busca na elaboração e padronização das demonstrações contábeis do governo, além de normas gerais de direito financeiro e controle dos orçamentos.

Entretanto, somente com a LRF/2000 efetivou-se a valorização do controle externo, reforçando as funções dos Tribunais de Contas nas auditorias governamentais. Cavalheiro e Flores (2001, p. 18) discorrem sobre a responsabilidade das auditorias na avaliação de programas do governo, por meio das auditorias operacionais, que examinam a ação governamental sob os aspectos da economicidade, eficiência e eficácia, bem como das auditorias de programas, que examinam o impacto da ação governamental e o resultado produzido por um programa.

Para Remyrech (2005), a interação das atividades entre o controle interno, o controle externo e a administração, tende a permitir o alcance dos resultados intencionados, sejam financeiros, orçamentários ou patrimoniais, com a utilização de menos recursos, evitando desperdícios em atividades mais onerosas e corrigindo desvios em relação aos objetivos inicialmente definidos. Entende-se que um sistema de controle interno contempla os planos organizacionais, de acordo com a sua razão de existência, bem como a definição de mecanismos e procedimentos que assegurem confiabilidade nas informações.

Além dos controles necessários, infere-se que o monitoramento de desempenho, a fixação de metas e a qualificação dos serviços públicos são instrumentos que melhoram a gestão financeira e aumentam a responsabilidade dos servidores (CARDOSO; SANTOS, 2001).

A importância da utilização das variáveis de desempenho nos programas governamentais é fundamental, pois a Portaria n $^{\circ}$ 42/99 do Ministério do Orçamento e Gestão definiu a avaliação do Plano Plurianual (PPA) mediante indicadores capazes de evidenciar possíveis alterações (CAVALHEIRO; FLORES, 2001).

O PPA foi instituído na intenção de integrar planejamento, gestão e recursos humanos nos órgãos públicos. Assim, o PPA deveria alocar um gerente em cada programa para direcioná-lo de acordo com as orientações estratégicas do governo (SANTOS, 2003). Porém, na prática isso ainda não ocorre de maneira plena, em razão de situações imprevistas (DAVIS; BLASCHEK, 2006).

Com a LRF/2000 o desenvolvimento de mecanismos de gestão mais apurados passou a ser exigido das entidades públicas, dentre os quais se destaca a implantação de um sistema de custos para a contabilidade pública, com a identificação e classificação correta dos eventos, para uma mensuração contábil mais eficiente e atender o princípio da economicidade (SANTOS et al., 2008).

R. Cont. Ufba, Salvador-Ba, v. 8, n. 3, p. 05 - 20, set-dez 2014 
Observa-se, então, a importância desses instrumentos para dotar os gestores públicos de informações relevantes ao controle dos recursos que são movimentados para atender aos serviços que são prestados pelo governo aos cidadãos, intensificando a importância das auditorias governamentais na avaliação de desempenho, analisando a economicidade, produção, produtividade e transparência da gestão.

Percebe-se que as evoluções tecnológicas auxiliaram na formulação de instrumentos de controle na gestão dos projetos e processos administrativos públicos, devido às exigências estabelecidas pela LRF, buscando atualização, desenvolvimento dos servidores públicos, usuários e responsáveis pela alimentação dos sistemas informatizados.

Tais técnicas aperfeiçoam os procedimentos internos do governo de modo que a eficiência possa ser internalizada nos diversos níveis de gestão. Nos comentários de Bezerra Filho (2002), a eficiência visa ao alcance do melhor desempenho na operacionalidade das ações de competência da organização e a eficácia ocorre no alcance dos objetivos preestabelecidos.

Ao tratar de um Estado mais produtivo, o INAP (1997) destaca que para medir os níveis de produtividade governamental existem dois grandes problemas: os determinantes envolvidos não são bem definidos e os altos graus de abstração implicam em resultados distantes daqueles desejados pela eficiência gerencial. Percebe-se que as informações assimétricas influenciam nas diferenças existentes entre os órgãos do próprio governo; não refletindo a realidade local. O relato de Rezende, Slomski e Corrar $(2005$, p. 26) remete que "cada vez mais os gestores públicos buscam instrumentos que propiciem avaliar o desempenho social das instituições públicas, a fim de diminuir a assimetria informacional entre sociedade e atividades do Estado". As mudanças abordadas relacionam-se aos esforços orientados para a transparência da gestão das finanças públicas e que se destinam também a "atender interesses gerais dos demais agentes econômicos, notadamente no que tange à minimização dos efeitos não desejados da assimetria de informações" (BERGUE, 2001, p. 15).

A transparência nos atos do governo conduz ao efeito esperado quanto à minimização de possíveis distorções informacionais que comprometam a acurácia entre o que foi obtido e o que consta nos registros. Em suma, desenvolver uma gestão eficiente em âmbito governamental relaciona-se à racionalização dos gastos, aplicando adequadamente os recursos disponíveis, contemplando os diversos atores nesse cenário.

\subsection{O PNAFM como programa modernizador dos Municípios brasileiros}

O Governo Federal moldou como programa o PNAFM na ótica de promover o acesso aos recursos disponíveis pelos municípios que visassem aperfeiçoar suas estruturas internas.

Conforme Santos et al (2008) a Constituição Federal determinou o aumento da destinação de recursos aos Municípios, com a finalidade de prover os serviços locais.

A partir de então, a implantação de práticas modernizadas na gestão pública proporcionou ao governo uma melhor arrecadação, aliada à otimização dos gastos públicos, caracterizando uma gestão fiscalmente equilibrada, a fim de atender às demandas sociais, competir igualmente com economias de outros países e achatar as desigualdades de diversas naturezas, oportunizando o acesso aos bens e serviços produzidos pelo Estado e de acesso à cidadania (BRASIL, 2009). No entanto, percebe-se que esses procedimentos para o gerenciamento dos municípios, ainda não são frequentemente encontrados, pois estes apresentam maior dificuldade em implantá-los e moldá-los conforme suas necessidades.

Desse modo, especialmente a tecnologia da informação viabilizou novas técnicas de comunicação e processamento de dados, como no caso da transmissão dos dados eletrônicos à Secretaria do Tesouro Nacional e os programas de auditoria dos Tribunais de Contas do Estado,

R. Cont. Ufba, Salvador-Ba, v. 8, n. 3, p. 05 - 20, set-dez 2014 
influenciando que as instituições públicas passassem a desenvolver suas atividades com acompanhamento de modo contínuo e detalhado pelas outras esferas do Governo.

Nesse cenário, somente em 2001, ocorreu a concepção efetiva do PNAFM, para buscar a estabilidade macroeconômica por meio do equilíbrio fiscal e sustentabilidade financeira. Este programa foi considerado como alternativa viável e fundamentada na política transparente, na gestão da receita eficiente e na racionalização dos gastos dos Municípios brasileiros (BRASIL, 2009).

A partir da parceria entre Governo Federal e Banco Interamericano de Desenvolvimento (BID), foi formatado o projeto que tem como órgão executor a Secretaria Executiva do Ministério da Fazenda, representada pela Unidade de Coordenação de Programas (UCP) e, como agente financeiro, a Caixa Econômica Federal (CEF), denominado co-executor de programa (BRASIL, 2009).

Nos Municípios participantes do programa com até 50.000 habitantes são ofertados projetos simplificados, ao passo que para Municípios acima desse limite destinam-se projetos considerados ampliados (BRASIL, 2009).

O Contrato de empréstimo BID 1194/OC-BR e o Regulamento Operativo do Programa PNAFM classificam os investimentos a serem efetuados nas seguintes categorias: na capacitação de servidores, na contratação de consultorias, na modernização da área de tecnologia da informação, na aquisição de equipamentos de apoio e comunicação, na expansão e modernização de infraestrutura e ajustes dos quadros efetivos de pessoal (BRASIL, 2009).

O PNAFM procura capacitar o sistema público visando mitigar custos e potencializar receitas, atingindo, dessa forma, o grau de eficiência necessária a sua manutenção. Conforme instruções divulgadas pelo Ministério da Fazenda, o prazo para execução do objeto é de até 5 anos e o prazo de carência é igualmente em até 5 anos, sendo que neste período há incidência do pagamento dos juros correspondentes. As formas de amortizações do contrato são previstas como semestrais e consecutivas, de modo que a taxa de juros é determinada pelo BID e refixada no mesmo período (BRASIL, 2010).

A partir de início de 2010, o PNAFM - segunda fase - entrou em vigor para contemplar ações de modernização da gestão administrativa e fiscal, tais como: a capacitação de técnicos e de gestores municipais, implementação de ações e sistemas destinados ao controle da arrecadação, modalidades de atendimento ao cidadão, sistemas de comunicação de dados, controle financeiro, recursos humanos, consultorias, aquisição de equipamentos de informática, infraestrutura e geoprocessamento referenciado. De modo complementar, ainda possibilita ao município a elaboração e implementação de Plano Diretor, do Cadastro Multifinalitário e também da Planta Genérica de Valores (BRASIL, 2010).

Com isso, serão privilegiadas as ações de integração dos fiscos, tais como: "a implantação do Cadastro Sincronizado Nacional (CadSinc) e do Sistema Público de Escrituração Digital (SPED), incluindo seus três subprojetos: Nota Fiscal Eletrônica (NF-e), Escrituração Fiscal Digital (EFD) e Escrituração Contábil Digital (ECD)" (BRASIL, 2010).

No entanto, percebe-se que para a aprovação do projeto de contratação do programa, são solicitadas declarações para a comprovação da regularidade dos órgãos municipais, especialmente quanto ao atendimento aos requisitos de limites estabelecidos pela LRF/2000 e às certidões emitidas pelos Tribunais de Contas do Estado - TCE. O efeito disso acaba por retirar a possibilidade de adesão daqueles municípios que não estão enquadrados nas exigências da LRF/2000, ou que ainda, quando encontram restrições nas auditorias públicas dos TCEs ou são considerados como inadimplentes junto a União por não atender às prestações de contas em prazo hábil. Esses limitadores, aliada a possível dificuldade financeira interna em prover recursos como contrapartida orçamentária e financeira restringe a possibilidade de que um volume maior de interessados possa manifestar interesse em pleitear esses recursos.

R. Cont. Ufba, Salvador-Ba, v. 8, n. 3, p. 05 - 20, set-dez 2014 
Nesse cenário, a modernização da estrutura pública torna-se fundamental, pois a gestão de resultados reverte em benefício da própria população, mediante a maximização da receita, transparência pública, planejamento e controle de desempenho orçamentário, aperfeiçoamento do sistema de arrecadação e atendimento ao cidadão, não se desviando da sua verdadeira missão institucional, que é o gerenciamento eficiente dos recursos do governo.

\section{PROCEDIMENTOS METODOLÓGICOS}

O projeto do PNAFM contava, na data base de final de 2009, com 86 Municípios brasileiros em fase de implementação nas etapas da execução. No Estado do Rio Grande do Sul essa representatividade era de somente oito (08) municípios, os quais são objeto desse estudo: Alvorada, Canoas, Passo Fundo, Santa Cruz do Sul, Santa Maria, Santa Rosa, São Gabriel e Três de Maio, sendo somente este último com projeto simplificado (BRASIL, 2009).

Esta pesquisa segundo Diehl e Tatim (2004) delinea-se por uma survey, com forma descritiva, de cunho qualitativo. Os dados gerais foram coletados junto ao site do Ministério da Fazenda com base no período de 2007 a 2009 e, após, buscou-se através de um questionário levantar as percepções dos responsáveis pelas Unidades de Execução Municipal (UEM),pois são os gestores do programa nos municípios. As UEMs são compostas pelo servidor encarregado da coordenação e seus auxiliares.

O questionário foi delineado com questões fechadas, com os seguintes critérios para resposta: 1 para sim, 2 para não e 3 para sem condições de responder ou não definido. As questões foram moldadas no sentido de apresentar um nível de informações capaz de proporcionar a relação entre as variáveis na amostra selecionada, tornando possível um estudo comparativo dos resultados (MARTINS; THEÓPHILO, 2007).

Inicialmente foi aplicado um pré-teste junto aos servidores da Secretaria de Planejamento de uma prefeitura que intenciona firmar esse projeto nos próximos anos, no sentido de validar o instrumento proposto e detectar ajustes necessários para a coleta das informações na amostra. $\mathrm{O}$ instrumento de coleta de dados foi direcionado por e-mail aos respondentes, no período que compreende os meses de outubro e dezembro de 2009, abrangendo todos os municípios pesquisados e com um retorno integral.

Para melhor contextualizar, o PNAFM adota como metodologia legal para a liberação dos recursos necessários à concretização das atividades, através da assinatura de contrato, com as disposições das cláusulas que garantem a correta aplicação dos recursos e o montante disponibilizado, conforme informações da Tabela 1:

Tabela 1: Informações contratuais do projeto PNAFM na amostra selecionada

\begin{tabular}{l|c|c}
\hline \multicolumn{1}{c|}{ Município } & Data do contrato & Valor do contrato (R\$) \\
\hline Alvorada & $20 / 12 / 2007$ & 6.256 .683 \\
\hline Canoas & $22 / 01 / 2004$ & 6.191 .600 \\
\hline Passo Fundo & $16 / 03 / 2006$ & 4.555 .938 \\
\hline Santa Cruz do Sul & $21 / 09 / 2006$ & 3.284 .705 \\
\hline Santa Maria & $26 / 08 / 2002$ & 6.227 .485 \\
\hline Santa Rosa & $14 / 01 / 2003$ & 1.801 .131 \\
\hline São Gabriel & $02 / 07 / 2004$ & 1.801 .659 \\
\hline Três de Maio & $01 / 07 / 2004$ & 300.381 \\
\hline
\end{tabular}

Fonte: Ministério da Fazenda (2009)

Já na Tabela 2 demonstram-se as atividades já desenvolvidas pela amostra estudada na posição acumulada em Dezembro/2009:

R. Cont. Ufba, Salvador-Ba, v. 8, n. 3, p. 05 - 20, set-dez 2014 
Tabela 2: Atividades prescritas no projeto do PNAFM com valores acumulados até 2009 na amostra selecionada (R\$)

\begin{tabular}{l|c|c|c|c|c|c}
\hline Município & Capacitação & Consultoria & $\begin{array}{c}\text { Equip. de } \\
\text { informática }\end{array}$ & $\begin{array}{c}\text { Equip. de } \\
\text { apoio }\end{array}$ & Infraestrutura & Total (R\$) \\
\hline Alvorada & 30.062 & 47.515 & 24.642 & - & - & $\mathbf{1 0 2 . 2 1 9}$ \\
\hline Canoas & - & 2.086 .210 & 395.577 & 321.635 & 787.257 & $\mathbf{3 . 5 9 0 . 6 7 9}$ \\
\hline $\begin{array}{l}\text { Passo } \\
\text { Fundo }\end{array}$ & 287.398 & 498.620 & 1.525 .736 & 131.921 & - & $\mathbf{2 . 4 4 3 . 6 7 5}$ \\
\hline $\begin{array}{l}\text { Santa Cruz } \\
\text { do Sul }\end{array}$ & 52.132 & 68.113 & 389.673 & 6.000 & - & $\mathbf{5 1 5 . 9 1 8}$ \\
\hline Santa Maria & 357.168 & 1.071 .000 & 2.156 .335 & 749.866 & 1.844 .600 & $\mathbf{6 . 1 7 8 . 9 6 8}$ \\
\hline Santa Rosa & 169.368 & 467.339 & 481.690 & 84.565 & 497.047 & $\mathbf{1 . 7 0 0 . 0 0 9}$ \\
\hline São Gabriel & 6.610 & 275.300 & 175.950 & 197.198 & 511.179 & $\mathbf{1 . 1 6 6 . 2 3 7}$ \\
\hline
\end{tabular}

Fonte: Ministério da Fazenda (2009)

A partir de 2010, foi instituída a segunda etapa que o programa prevê aos municípios já contratados, a qual não consiste como objeto desse estudo.

\section{RESULTADOS DA PESQUISA}

Nesta seção são apresentados os dados relacionados ao PNAFM nos Municípios pesquisados e a percepção dos responsáveis pelas unidades gestoras.

\subsection{Caracterização do PNAFM nos municípios gaúchos estudados}

Os dados expostos na Tabela 1 apontam que o Município com maior volume de recursos contratados até o período desse estudo, é o município de Alvorada, seguido por Santa Maria. Infere-se que em todos os locais estudados estes valores estão agrupados nas diversas atividades que envolvem o objeto contratual pactuado, classificadas em investimentos básicos que abrange as capacitações, consultorias, aquisição de equipamentos de informática e apoio, bem como a classificação de infraestrutura administrativa, a qual reflete a busca por melhores condições físicas de gerenciamento do setor público municipal.

Em relação aos dados da Tabela 2, salienta-se que se referem somente aos Municípios com projetos ampliados, enquanto que o município de Três de Maio possuía um projeto simplificado, não constando os dados na base consultada do Ministério da Fazenda. Percebe-se que a concentração dos recursos é relativa à contratação de consultorias e na aquisição de equipamentos de informática. Já o quesito capacitação detém os maiores valores com aplicação em Santa Maria, seguida por Passo Fundo e Santa Rosa, valores estes destinados a melhor preparação dos servidores nas atividades relacionadas ao foco do projeto.

No que se refere às infraestruturas, constam as reformas, as construções e adequações de espaços físicos como investimentos prioritários no escopo do PNAFM. Em quatro dos locais estudados foram previstas novas instalações físicas dos setores administrativos, garantindo aos servidores melhores condições de trabalho, com um ambiente organizado e estruturado.

Nas informações de caráter geral, ainda contatou-se o disposto na Tabela 3 como relevantes ao entendimento da pesquisa, considerando que o programa encontrava-se em execução nos locais estudados:

Tabela 3: Informações Gerais do PNAFM - Base final de 2009

R. Cont. Ufba, Salvador-Ba, v. 8, n. 3, p. 05 - 20, set-dez 2014 


\begin{tabular}{|c|c|c|c|c|c|c|c|c|}
\hline & Alvorada & Canoas & $\begin{array}{l}\text { Passo } \\
\text { Fundo }\end{array}$ & $\begin{array}{l}\text { Santa } \\
\text { Cruz Sul }\end{array}$ & $\begin{array}{l}\text { Santa } \\
\text { Maria }\end{array}$ & $\begin{array}{l}\text { Santa } \\
\text { Rosa }\end{array}$ & \begin{tabular}{|l|} 
São \\
Gabriel
\end{tabular} & $\begin{array}{l}\text { Três de } \\
\text { Maio }\end{array}$ \\
\hline $\begin{array}{l}\text { Tempo de } \\
\text { formalização do } \\
\text { projeto (anos) }\end{array}$ & 4 & 5 & 5 & 5 & 4 & 4 & 5 & 4 \\
\hline $\begin{array}{l}\text { Tempo previsto } \\
\text { de execução } \\
\text { (anos) } \\
\end{array}$ & 4 & 4 & 5 & 4 & 5 & 4 & 4 & 4 \\
\hline $\begin{array}{l}\text { Pessoas na } \\
\text { equipe gestora }\end{array}$ & 5 & $\begin{array}{c}\text { Acima de } \\
5\end{array}$ & $\begin{array}{c}\text { Acima de } \\
5\end{array}$ & 5 & $\underset{5}{\text { Acima de }}$ & $\begin{array}{l}\text { Acima de } \\
5\end{array}$ & 5 & 4 \\
\hline $\begin{array}{l}\text { \% do projeto } \\
\text { concluído }\end{array}$ & $\begin{array}{l}\text { Abaixo de } \\
50 \%\end{array}$ & $\begin{array}{c}\text { Acima de } \\
50 \%\end{array}$ & $\begin{array}{c}\text { Acima de } \\
50 \%\end{array}$ & $\begin{array}{l}\text { Abaixo } \\
\text { de } 50 \%\end{array}$ & $\begin{array}{c}\text { Acima de } \\
50 \%\end{array}$ & $\begin{array}{l}\text { Acima de } \\
50 \%\end{array}$ & $\begin{array}{l}\text { Acima de } \\
50 \%\end{array}$ & $\begin{array}{c}\text { Acima de } \\
50 \%\end{array}$ \\
\hline
\end{tabular}

Fonte:UEMs dos municípios estudados

Observa-se pela Tabela 3 que o tempo médio de formalização dos projetos nos Municípios estudados foi entre quatro e cinco anos, relacionado ao longo período para a aprovação nas instâncias de análise devido ao elevado nível de informações que devem ser prestadas aos órgãos financiadores e aos estudos complexos de viabilidade econômico-financeira que compõem o projeto.

O tempo previsto para a efetiva execução foi estimado entre quatro e cinco anos, considerando ainda que dentro deste prazo devem ocorrer as prestações de contas parciais, sendo que em excepcionalidades justificadas, estas poderão obter prorrogações de vigência.

Com relação ao número de pessoas que compõem a equipe gestora, destaca-se que em média, os Municípios deslocaram cinco servidores para essa composição, de modo que somente o município de Três de Maio apresentou quatro pessoas na equipe, por se configurar em projeto simplificado. No que se refere ao percentual do projeto já concluído até este estudo, somente dois locais detinham índice inferior a 50\% de execução efetiva.

\subsection{Resultados do questionário sobre a adesão ao PNAFM}

Através do questionário delineado, buscaram-se as informações acerca das percepções dos respondentes com a implantação do PNAFM em cada Município, conforme se apresenta no Quadro 1:

Quadro 1: Questões direcionadas aos responsáveis pela UEM nos locais estudados

\begin{tabular}{|l|c|c|c|}
\hline \multicolumn{1}{|c|}{ Questões } & Sim (\%) & Não (\%) & $\begin{array}{c}\text { Sem condições } \\
\text { de responder } \\
\text { (\%) }\end{array}$ \\
\hline $\begin{array}{l}\text { 1) Quando implementado o PNAFM em seu município, } \\
\text { foram encontradas restrições internas junto aos servidores? }\end{array}$ & 100,0 & - & - \\
\hline $\begin{array}{l}\text { 2) Existe monitoramento da equipe gestora sobre as ações } \\
\text { internas implantadas com o programa? }\end{array}$ & 62,5 & 37,5 & - \\
\hline $\begin{array}{l}\text { 3) Foram implementados indicadores de desempenho para } \\
\text { avaliar o programa? }\end{array}$ & 25,0 & 75,0 & - \\
\hline $\begin{array}{l}\text { 4) Em seu município, já foi implantado o planejamento } \\
\text { estratégico como instrumento de gestão? }\end{array}$ & 75,0 & 25,0 & \\
\hline $\begin{array}{l}\text { 5) Foram destinados pelo Programa recursos para a } \\
\text { qualificação dos servidores municipais? }\end{array}$ & 100,0 & - & - \\
\hline $\begin{array}{l}\text { 6) Há previsão de institucionalização da Escola de Gestão } \\
\text { Pública em seu município conforme propõem o programa? }\end{array}$ & 75,0 & 25,0 & \\
\hline $\begin{array}{l}\text { 7) Caso sim, a Escola de Gestão Pública já encontra-se em } \\
\text { funcionamento? }\end{array}$ & 37,5 & 62,5 & - \\
\hline
\end{tabular}




\begin{tabular}{|l|c|c|c|}
\hline $\begin{array}{l}\text { 8) Através dos cursos de qualificação já desenvolvidos, foi } \\
\text { possível detectar melhoria nos procedimentos realizados } \\
\text { pelos servidores? }\end{array}$ & 12,5 & 87,5 & - \\
\hline $\begin{array}{l}\text { 9) Através do PNAFM, já foram definidos novos } \\
\text { organogramas, planos de carreira e definição de funções } \\
\text { gratificadas em seu município? }\end{array}$ & 100,0 & - & \\
\hline $\begin{array}{l}\text { 10) Já foi implantado os sistemas informatizados para } \\
\text { integrar as diversas áreas de gestão? }\end{array}$ & 62,5 & 37,5 & - \\
\hline $\begin{array}{l}\text { 11) A implantação da avaliação integrada de resultados da } \\
\text { gestão financeira, orçamentária e do Plano Plurianual já foi } \\
\text { realizada em seu município? }\end{array}$ & - & 37,5 & 62,5 \\
\hline $\begin{array}{l}\text { 12) O Programa permite a gestão participativa entre as } \\
\text { diversas áreas da administração pública municipal? }\end{array}$ & 100,0 & - & \\
\hline $\begin{array}{l}\text { 13) Na sua percepção, o Programa contribui para a eficiência } \\
\text { administrativa municipal e na melhoria dos processos } \\
\text { internos? }\end{array}$ & 75,0 & 25,0 & - \\
\hline
\end{tabular}

Fonte: Baseado no PNAFM (BRASIL, 2009)

Primeiramente, quanto ao processo de mudança na gestão, as respostas indicam que foram encontradas restrições (resistências) internas quanto à efetivação das propostas na totalidade da amostra, provocadas principalmente pela modernização dos fluxos de atividades e pelas novas rotinas que seriam implantadas ao longo do período de execução do programa.

Quanto ao monitoramento pela equipe gestora das ações propostas pelo programa, observa-se que $62,5 \%$ dos locais efetuam este tipo de controle, visto que esse processo é fundamental para detectar possíveis falhas ou inconsistências a serem sanadas enquanto o projeto estiver sendo implantado. Destaca-se que São Gabriel, Santa Rosa e Três de Maio não haviam implantado ainda desse procedimento específico.

Quanto à formulação de indicadores de desempenho, essencial para avaliar a eficiência do programa mediante as suas propostas, constatou-se que somente em dois locais tais instrumentos de gestão foram implantados, enquanto que nos demais, ainda permaneciam na fase de construção dos modelos de medição.

No que diz respeito a implantação do planejamento estratégico como instrumento de gestão, constatou-se que em todos dos Municípios estudados, o PNAFM prevê esse instrumento como parte integrante dos objetivos propostos. No entanto, somente $75 \%$ dos respondentes informaram que já ocorreu o seu desenvolvimento efetivo, mas em dois municípios as diretrizes do planejamento estratégico de forma ampliada, quando comparado o Plano Plurianual, se encontravam em fase de ajustes, no período do estudo. Entende-se que planejar estrategicamente uma entidade é de fundamental importância e os municípios necessitam implementar esse instrumento para prover informações mais acuradas e, consequentemente, planejar adequadamente o futuro das cidades.

Outro tópico questionado foi a qualificação dos servidores, verificando-se que em $100 \%$ da amostra foi afirmada a existência de recursos para tal finalidade, item essencial à motivação e ao bom desempenho das organizações. Paralelamente, em $75 \%$ destes há previsão da instituição de escola permanente de gestão para a qualificação interna, mas em somente $37,5 \%$ dos locais essa estrutura encontrava-se em funcionamento.

O PNAFM ao prever recursos para melhor qualificar os servidores, procura alinhar essa etapa aos resultados mais otimizados ao longo do tempo, permitindo com isso dotar de procedimentos diários que possibilitem avançar na agilidade dos atendimentos administrativos, sejam aos usuários internos ou externos, que demandam por informações contínuas.

Em relação aos novos procedimentos adotados pelos servidores após a realização de cursos específicos, observou-se em $87,5 \%$ dos locais que os respondentes informaram como não

R. Cont. Ufba, Salvador-Ba, v. 8, n. 3, p. 05 - 20, set-dez 2014 
identificado nos resultados esperados, enquanto que somente um dos municípios manifestou a efetivação prática de novas metodologias de trabalho com os treinamentos realizados.

Aliado a isso, foi questionado se os Municípios realizaram estudos de recursos humanos e implantaram novos organogramas, planos de carreira e definição de funções gratificadas, sendo possível identificar de modo unânime essas novas formatações em âmbito administrativo, estabelecendo um sincronismo entre as atividades desenvolvidas e as responsabilidades inerentes às unidades municipais, no caso as secretarias.

Além disso, quanto a implantação de sistemas informatizados integrados nas diversas áreas da gestão, principalmente na tributária, as respostas indicam que conforme foi definido no programa, isso repercutiu positivamente em $62,5 \%$ da amostra estudada. Esta modernização inclui a geração de informações mais precisas e disponíveis eletronicamente aos cidadãos, de modo a tornar mais ágil os processos administrativos, proporcionando um eficiente controle financeiro e fiscal.

Ao questionar sobre a implantação da avaliação de resultados da gestão orçamentária e do Plano Plurianual, 62,50\% dos respondentes afirmaram não ter certeza ou condições de responder e $37,5 \%$ disseram que o programa não prevê o desenvolvimento desse instrumento como forma de mensurar a gestão estratégica no setor público. O uso desse instrumento como medida de desempenho, se não utilizado, poderá fazer com que o setor público deixe de detectar problemas orçamentários e possíveis falhas na administração, ou ainda, a destinação correta dos recursos arrecadados comparado ao definido nos orçamentos, uma vez que a falta de informação para o diagnóstico dos cenários, pode influenciar nos resultados e comprometer a eficiência governamental.

No estudo buscou-se identificar se o programa ora estudado, permite a gestão participativa entre as diversas áreas da gestão, os respondentes afirmaram positivamente de forma unânime, demonstrando uma maior participação, senso de comunicação e troca de ideias construtivas no processo de gestão compartilhada.

Por fim, ao indagar sobre a contribuição do programa para a eficiência administrativa municipal e a contribuição deste para a melhoria dos processos internos, $75 \%$ dos responsáveis pelas UEMs responderam que os resultados convergem para essa prática e que influenciaram na agilidade dos trâmites internos, em razão da reforma administrativa realizada pela adesão ao programa.

\section{CONCLUSÃO}

A modernização do setor público se constituiu no elemento norteador da busca por melhores resultados e na aproximação com as práticas adotadas pela administração privada. Um dos programas instituídos para financiar a modernização municipal no Brasil, é o PNAFM, cujo objetivo engloba a estrutura administrativa e as percepções quanto ao programa, para uma gestão eficiente e equilibrada fiscalmente, por meio da racionalização dos gastos e do aumento dos níveis de recursos arrecadados.

Assim, este estudo centrou-se nos Municípios do Estado do Rio Grande do Sul que aderiram ao PNAFM, com o objetivo de identificar as percepções dos gestores do programa, especialmente, no sentido de estímulo à eficiência governamental, bem como se os resultados convergem para o foco estabelecido pelo programa.

A metodologia empregada foi de cunho descritivo, com enfoque qualitativo, tendo como base oito Municípios gaúchos que já apresentavam ações em andamento oriundas do Programa nos anos de 2007 a 2009. 
Em linhas gerais, evidenciou-se nos Municípios pesquisados que o PNAFM tem proporcionado mudanças significativas no que se refere às novas metodologias de trabalho, como: a implantação do planejamento estratégico para projetar as ações locais promovendo maior sustentabilidade dos governos de forma ampla e por um período superior ao definido no Plano Plurianual; na formalização de organogramas administrativos, planos de carreira e definições de funções como modo de ajustar internamente a gestão administrativa dos municípios envolvidos no programa; a utilização de sistemas informatizados mais avançados para agilizar os processos internos e, por fim, a gestão participativa entre as diversas áreas dos municípios formam um percentual médio positivo em na totalidade dos locais pesquisados.

Salienta-se, que no diz respeito ao quesito eficiência administrativa, em torno de $75 \%$ dos respondentes afirmaram serem visíveis as melhorias nos processos internos e na agilidade da execução das tarefas, caracterizando uma evolução importante nos trâmites e fluxos de trabalho. No entanto, alguns quesitos merecem atenção quanto aos seus resultados, como: as possíveis restrições às mudanças por parte dos servidores; a não implantação de indicadores de desempenho para o acompanhamento das atividades indicadas pelo processo de melhoria do programa; a não implantação das escolas de gestão previstas como alternativa ao processo de qualificação profissional dos servidores públicos para estimular melhor aprendizado nas atividades executadas e, também, a ausência de melhoria nos procedimentos realizados pelos servidores em grande parte dos locais pesquisados.

Isso reflete diretamente nas ações previstas quando foi assinado o contrato e, especialmente, quando foi gerada uma expectativa como retorno da adesão ao programa, inviabilizando o processo de aprendizado contínuo, pois ainda não foram consolidados pelo programa.

Ao final, conclui-se que, mesmo com quesitos com baixa efetivação encontrada nas respostas, a ampliação sistemática de novas linhas de crédito direcionadas aos Municípios, no que tange a reformulação de processos internos e de reorganização funcional dos servidores, gera melhores resultados à gestão municipal, principalmente na estrutura administrativa e nas condições de modernização das estruturas físicas com a utilização de recursos tecnológicos, formando o ambiente mais organizado e voltado aos resultados mais efetivos na administração municipal. Espera-se que novos estudos complementares possam ser desenvolvidos para apresentem resultados mais atuais e, com isso, que seja ampliada a discussão sobre essa temática nas estruturas de governo municipais.

\section{REFERÊNCIAS BIBLIOGRÁFICAS}

BERGUE, Sandro Trescastro. Sistemas de Planejamento e Controle Interno e a Análise de Desempenho Baseada em Indicadores de Eficácia: a proposição de uma abordagem da despesa pública em educação focada no programa de ensino fundamental no município de Cerro Grande do Sul. Revista do BNDES. $1^{a}$ parte, Agosto, 2001. Disponível em http://www.bndes.gov.br/SiteBNDES/bndes/bndes_pt/Areas_de_Atuacao/Desenvolvimento_ Social_e_Urbano/Banco_Federativo/20010823_1.html Acesso em: 20 janeiro 2010.

BEZERRA FILHO, João Eudes. Uma metodologia para a avaliação da eficiência e eficácia na gestão dos recursos públicos. IN: ENANPAD, Salvador, 2002. Anais do $26^{\circ}$ Enanpad, Bahia: Salvador, 2002. CD-ROW.

BRASIL. Ministério da Fazenda. Unidade de Coordenação de Programas: Quem somos? 2009. Disponível em: http://www.ucp.fazenda.gov.br. Acesso em: 10 Jan, 2010.

R. Cont. Ufba, Salvador-Ba, v. 8, n. 3, p. 05 - 20, set-dez 2014 
Caixa Econômica Federal. Disponível em: http://www1.caixa.gov.br.

Acesso em: 12 Jan. 2010.

. Ministério da Fazerda - Unidade de Coordenação de Programas, PNAFM,

2009. Disponível em: http://www.ucp.fazenda.gov.br/ . Acesso em 11 dez. 2009.

Lei de Responsabilidade Fiscal. Lei Complementar 101/2000. Disponível

em: http://planalto.gov.br/ccivil_03/leis/lcp/lcp101 Acessado em: 08 Jan. 2010.

BRESSER PEREIRA, Luiz Carlos. Da administração pública burocrática à gerencial. Revista do Serviço Público. Escola Nacional de Administração Pública - ENAP, n. 46, 1996.Disponível em:

http://www.bresserpereira.org.br/papers/1996/95.AdmPublicaBurocraticaAGerencial.pdf. Acesso em: 07 Jan. 2010.

CARDOSO, Luiz Alberto dos Santos; SANTOS, Regina Luna dos. Avaliação de Desempenho da ação governamental no Brasil: problemas e perspectivas. Anais XV Concurso de Ensayosdel CLAD "Control y EvaluacióndelDesempeñoGubernamental". Caracas, 2001. Disponível em:

http://2009.campinas.sp.gov.br/rh/uploads/egds_material/txt_apoio_avaliacao_desempenho_a cao.pdfAcesso em: 04 Jan. 2010.

CAVALHEIRO, Jader Branco; FLORES Paulo César. O planejamento governamental na LRF como forma de aplicação do gerenciamento por resultados e o equilíbrio das contas públicas. VII Convenção de Contabilidade do Rio Grande do Sul, Gramado, Agosto de 2001. Disponível em:http://www.bndes.gov.br/clientes/federativo/bf_bancos/e0001749.pdf. Acesso em: 15 Jan. 2010.

DAVIS, Marcelo David; BLASCHEK, José Roberto de Souza. Deficiências dos sistemas de controles internos governamentais atuais em função da evolução da economia. In: Anais do CONGRESSO DE CONTROLADORIA E CONTABILIDADE, 6. 2006. Disponível em http://www7.rio.rj.gov.br/cgm/academia/artigos/arquivos/2005/02.pdfAcesso em: 15 Jan. 2010.

DIEHL, Astor Antônio; TATIM, Denise Carvalho. Pesquisa em ciências sociais aplicadas: métodos e técnicas. São Paulo: Person Prentice Hall, 2004.

INAP, Instituto Nacional de La Administración Pública. Evaluación em la gestión pública: conceptualización, modalidades y nuevas perspectivas. INAP, Buenos Aires, 1997.

Disponível em

R. Cont. Ufba, Salvador-Ba, v. 8, n. 3, p. 05 - 20, set-dez 2014 
http://www.sgp.gov.ar/contenidos/inap/publicaciones/docs/capacitacion/evaluacion_GP.pdf Acesso em: 15 de Dez. 2009.

GUIMARÃES, Tomás de Aquino; CAVALCANTI Henrique de V; AFFONSECA Maria Dulce Valença de. Gestão da qualidade e inovações gerenciais em organizações públicas. IN: ENANPAD, Curitiba/PR, 2004. Anais... do $28^{\circ}$ Enanpad, Paraná: Curitiba, 2004. Disponível em:

http://www.anpad.org.br/evento.php?acao=trabalho\&cod_edicao_subsecao=39\&cod_evento_ edicao=8\&cod_edicao_trabalho=1295. Acesso em: 06 Jan. 2010.

MARTINS, Gilberto de Andrade; THEÓPHILO, Carlos Renato. Metodologia da investigação científica para ciências sociais aplicadas. São Paulo: Atlas, 2007.

OSBORNE, David; GAEBLER Ted. Reinventando o Governo. 9ª ed., Brasília: MH Comunicações, 1997.

REIS, Luciano Gomes dos; SLOMSKI, Valmor; PEREIRA, Carlos Alberto; MELLO, Gilmar Ribeiro de. A pesquisa brasileira em contabilidade do setor público: uma análise após a implementação da Lei de Responsabilidade Fiscal. Revista da Informação Contábil (RIC/UFPE), v.1, n.1, p.89-101, set. 2007.

REMYRECH, Ruy. Controle interno na administração pública. Tribunal de Contas do Rio Grande do Sul, Porto Alegre,2005. Disponível em:

http://www.tce.rs.gov.br/artigos/pdf/controle-interno-administracao-publica.pdf. Acesso em: 07 Jan. 2010.

REZENDE, Amaury J.; SLOMSKI, Valmor; CORRAR, Luiz João. A gestão pública municipal e a eficiência dos gastos públicos: uma investigação empírica entre as políticas públicas e o índice de desenvolvimento humano (IDH) dos municípios do Estado de São Paulo. Revista Universo Contábil, Blumenau, v. 1, n. 1, p 24 - 40, jan./abr. 2005.

SANTOS, Alba Conceição Márquez dos. A administração Pública Gerencial. SEPLAG/RS, Porto Alegre, 2003. Disponível em:

http://www.seplag.rs.gov.br/uploads/AdministracaoPublicaGerencial.pdf. Acesso em: 18 Jan. 2010.

, Gustavo Antônio Galvão; TAVARES, Fernando Henrique; REIFF, Luís Otávio de Abreu; CORREAA, Letícia Vieira. Potencial de Arrecadação Municipal e o PMAT. Revista do BNDS, Rio de Janeiro, v.14, n. 29, p.399-434, jun. 2008. 